\title{
La comunalidad como base para la construcción de resiliencia social ante la crisis civilizatoria ${ }^{1}$
}

\author{
Mario Enrique Fuente Carrasco \\ Instituto de Estudios Ambientales de la Universidad de la Sierra Juárez, Oaxaca, México. \\ Email: fuente@juppa.unsij.edu.mx
}

\begin{abstract}
Resumen: La estela de la crisis del proyecto civilizatorio occidental ha agudizado las desigualdades sociales y alterado los procesos homeostáticos de la biosfera. El despojo sutil o violento de los territorios con alto potencial de recursos naturales es una astucia más del modelo neoliberal para paliar su crisis estructural; tal como sucede contra los pueblos indígenas. Estas acciones son altamente perturbadoras de las dinámicas de organización social, y de la agudización de injusticia ambiental. Sin embargo, diversos grupos sociales están reconfigurando sus estrategias no solo para resistir, sino para la construcción de alternativas. El ethos comunitario (comunalidad) -como un elemento cultural propio de los pueblos con ascendencia de la cultura mesoamericana- es una de estrategia intercultural fundamental para estas tareas. La noción de resiliencia social se usa como herramienta analítica de tal exploración. Se destaca que los grados de resiliencia de las comunidades están relacionados con la construcción de procesos autonómicos.
\end{abstract}

Palabras clave: comunalidad, resiliencia, racionalidad económica, crisis

\section{The commonality as a basis for building social resilience to the crisis of civilization}

\begin{abstract}
The trail of the crisis of Western civilizatory project has exacerbated social inequalities and altered homeostatic processes of the biosphere. The subtle or violent dispossession of territories with high potential of natural resources is another trickery of the neoliberal model to palliate its structural crisis; as happens against indigenous peoples. These actions are highly disruptive of the dynamics of social organization, and the worsening of environmental injustice. However, various social groups are reshaping their strategies not only to resist, but to build alternatives. The community ethos (comunalidad), -as an element of the peoples own cultural ancestry of Mesoamerican culture- is a critical intercultural strategy for these tasks. The notion of social resilience is used as an analytical tool in such exploration. It is noted that the degree of resilience of communities is related to the construction of autonomous processes.
\end{abstract}

Key words: community ethos, resilience, economic rationality, crisis

\section{A comunalidade como base para a construção de resiliência social à crise de civilização}

Resumo: A esteira da crise do projeto de civilização ocidental tem agrava- 
do as desigualdades sociais e alterado os processos homeostáticos da biosfera. A expropriação sutil ou violenta de territórios com alto potencial de recursos naturais é uma astúcia mais do modelo neoliberal para aliviar sua crise estrutural, como acontece contra os povos indígenas. Essas ações são extremamente perturbadores da dinâmica da organização social, e do agravamento da injustiça ambiental. No entanto, vários grupos sociais estão reformulando suas estratégias, não só para resistir, mas para construir alternativas. O ethos da comunidade (comum), -como um elemento dos povos que possui ascendência cultural da Mesoamérica- é uma estratégia intercultural indispensável para essas tarefas. A noção de resiliência social é usada como uma ferramenta analítica de tal exploração. Note-se que o grau de resiliência das comunidades estão relacionadas com a construção de processos autónomos.

Palavras-chave: comunalidade, resiliência, racionalidade econômica, crise

\section{Introducción}

Ante la crisis de la racionalidad económica, una de las estrategias del capital ha sido la de la exploración y extracción de un constante insumo de recursos naturales energéticos, minerales y genéticos; los cuales tienen un reservorio significativo en territorios indígenas. Ello ha generado fuertes perturbaciones en las comunidades indígenas, ya sea de manera legal ${ }^{2}$ (pero ilegítima) o través de medidas trágicas (como las acciones de shock). Las respuestas de los pueblos indígenas han sido diversas, pero destaca que su nivel de asociación comunitaria es un elemento clave para no solo resistir, sino superar dichos procesos con enseñanzas significativas en la construcción de una sustentabilidad.

Esta racionalidad económica, durante las últimas décadas, ha provocado el crecimiento de la desigualdad social (exclusión) y la alteración drástica de las propiedades homeostáticas mantenidas por los ecosistemas durante el holoceno. La implementación del mito de un crecimiento económico ilimitado -orientado a la mayor acumulación-, ha alterado los tiempos y ritmos biogeoquímicos de los ecosistemas, y con ello las tasas de renovabilidad o de sustitución de los insumos, así como la capacidad de absorción y reintegración de desechos emitidos a la naturaleza. La combinación de estas transformaciones se ha manifestado en un aumento de la injusticia ambiental. Los conflictos distributivos económicos impactan a los de tipo ambiental: al crecer y concentrar el capital (beneficios) se transfieren los costos (económicos, pero también ambientales) a amplios segmentos de la población, sobre todo de los países del sur. Esta crisis socioambiental es una manifestación del proyecto civilizatorio basado en el arraigo del tipo de racionalidad económica.

Ante la identificación de la globalización de los problemas socioambientales, desde la década de los años noventa se ha institucionalizado el discurso del desarrollo sostenible como astucia geopolítica para internalizar la dimensión ambiental dentro del paradigma 
de un crecimiento económico ilimitado. Sin embargo, desde este discurso no se pretende cuestionar las premisas de la racionalidad económica desde la cual se genera insustentabilidad.

El asunto es que la racionalidad económica capitalista es parte central del origen del problema socioambiental, por lo que tomar soluciones desde la misma racionalidad solo es una aporía (Elizalde, 2012). Para muestra dos botones: la manifestación de la crisis financiera declarada en el 2008 sigue exhibiéndose como una de las contradicciones del capitalismo en su fase neoliberal; sin embargo, siguen recetándose paliativos desde las mismas formulas, pero además evidenciado que la "mano invisible" requiere de la "mano cómplice" del Estado. Otro caso es la entropización del planeta manifestada como una alta concentración de gases efecto invernadero en la atmósfera, y su impacto en el calentamiento global. Desde el citado discurso de desarrollo sostenible el problema del cambio climático se trató de enfrentar como un asunto de desarrollo tecnológico, y sobre todo de mercado (internalización), tal como fue planteado a través de los mecanismos flexibles expresados en el protocolo de Kioto. Hoy el tema del cambio climático se muestra como el gran indicador de la crisis ambiental en su fase posprotocolo de Kioto.

En este entorno altamente perturbador, existen planteamientos diversos que indican que nuestra generación atestigua la segunda y última gran crisis del capitalismo. Mientras que para algunos autores estamos al borde de la crisis, otros señalan (Esteva, 2012) que ya estamos en el abismo de ella. En este entorno, en la academia ha saltado diversas nociones para comprender los niveles de flexibilidad que poseen las entidades sociales ante los diversos factores perturbadores (económicos y ambientales). Una dimensión clave en este asunto es la de tratar de construir conceptos que dé cuenta de un supuesto umbral en el cual los individuos o la sociedad puede dar respuestas positivas ante el efecto de las perturbaciones (negativas). La resiliencia social ha emergido en este contexto paradigmático de las ciencias sociales. La noción se retoma este trabajo desde un ángulo ético-político, pues es de interés especial trascender la idea de la valerosa resistencia de las entidades sociales hacia la construcción de respuestas alternativas. La resiliencia social se acerca a esta idea.

En países como México donde se han aplicado fielmente las formulas del descontinuado “conceso de Washington”, el impacto perturbador es mayor, pues no solo ha incluido una combinación de procesos sutiles (legaloides) y violentos. La ley de inversión extranjera, la cual tiene alta relación con el auge de la industria extractiva (mineral) en México, mas las recientes reformas en materia laboral y de la apertura de la empresa paraestatal de Petróleos Mexicanos son ejemplos simbólicos de la aplicación de las recetas neoliberales. Pero al mismo tiempo se manifiesta una fuerte asociación entre dos de las instituciones de la modernidad desencantada: el libre merado y la democracia representativa; las cuales han agudizado la polarización social ${ }^{3}$. El Estado y sus instituciones se han convertido agentes activos y administradores de los intereses del capital (poder fáctico); la 
democracia representativa se ha evidenciado como un instrumento de pretendida legitimidad y gobernabilidad. La estrategia fallida del gobierno mexicano frente al tema del narcotráfico (Morales, 2011) es un factor adicional a considerar como elemento perturbador del tejido social: más de 60 mil muertos equivale a la presencia de una guerra civil. Por último habrá que destacar los altos grados de vulnerabilidad que presenta el territorio mexicano frente los fenómenos naturosociales ${ }^{4}$; las inundaciones en Tabasco y Chiapas, las sequías en el norte del país, más otros incidentes como deslaves, impacto de huracanes e incendios sigue siendo una constante en la vida cotidiana del mexicano.

También habrá que señalar que los niveles de respuestas de la sociedad mexicana ante este entorno calamitoso ligado a la modernidad capitalista occidental y los citados fenómenos naturosociales no son homogéneos. En sociedades tan interculturales como lo expresan los pueblos indígenas, el umbral de la resiliencia no lo es de todo claro; pero ofrece reflexiones y lecciones políticas de alto interés en la construcción de alternativas ante el liberalismo exacerbado. Al respecto saltan diversas interrogantes: ¿Qué aspectos de la vida social de los pueblos indígenas ${ }^{5}$ se pueden considerar como talantes inherentes a su identidad? ¿Hasta que punto la tradición y la costumbre se está innovando constantemente para permanecer como entidad social?, o ¿̇hasta qué punto la permeancia de ciertos rasgos de la tradición fomentan su expiración? En su tiempo, Bonfil (1982; 2005) ya había reflexionado sobre la gran capacidad de los pueblos indígenas para reconfigurar sus estrategias ante el embate de elementos culturales ajenos; una de estas a través de su concepto de control cultural. En este ensayo se pone como hipótesis de trabajo que el ethos comunitario presente en los pueblos con ascendencia en la cultura mesoamericana se constituye en un elemento cultural clave frente al arrogante liberalismo. Es decir, que la construcción y reconfiguración del ethos comunitario es a su vez, una construcción de niveles de resiliencia social. La expresión territorial de tales respuestas en la reconfiguración de la comunidad se toma de la praxis de comunidades con ascendencia en la cultura mesoamericana de la Sierra Juárez de Oaxaca.

El abordaje se realiza desde cuatro ejes de análisis. En el primero se enfoca a matizar la noción de la resiliencia, tanto en sus orígenes y en sus expectativas como instrumento heurístico. La relevancia de la noción está ligada a la construcción de alternativas ante los efectos perturbadores, y no solo como resistencia. A partir de esta acotación la exposición se divide en tres aspectos interrelacionados: la identificación de la crisis del proyecto civilizatorio como catalizador de altas perturbaciones socioambientales; la caracterización de algunos componentes del ethos comunitario de comunidades con ascendencia en la cultura mesoamericana; y la descripción de factores vinculados - como la autonomía- con la construcción de una resiliencia social desde el ethos comunitario.

En este sentido, el trabajo valora como altamente pertinente la indagación de algunas de las respuestas de los pueblos indígenas. El análisis de 
tales réplicas esta matizada por el siguiente contexto: a) se derivan de matrices culturales diferentes a la racionalidad económica; b) presentan altos grados de interculturalidad, por lo que son dinámicas; c) lo comunitario frente a lo individual se ha constituido en un importante contribución y base de sus respuestas; d) dada la alta riqueza biológica y de recursos estratégicos (genéticos, minerales, energéticos) de sus territorios, durante las últimas tres décadas se han sido blanco de maniobras de despojo por parte de los poderes del estado y de las corporaciones; e) en sus territorios se han manifestado un conjunto de fenómenos naturosociales no presentes en otros tiempos (lluvias intensas, sequias, incendios forestales); f) por último, habrá que señalar que en estos pueblos se ubica gran parte del patrimonio biocultural de la humanidad (Stavenhagen, 2008 y Boege, 2008), y en esa medida han sido objeto de un proceso de biopiratería.

\section{La resiliencia social: acercamiento conceptual}

Ante la complejidad de problemas de tipo social, las áreas de las ciencias sociales han afiliado términos derivados de otras disciplinas como estrategias para la construcción de diversos paradigmas; sobre todo de las ciencias naturales como la física y la biología. El uso del paradigma de la evolución como estrategia analítica para justificar al individualismo metodológico y la competencia es un ejemplo del determinismo biológico más socorrido por las ciencias sociales. En el contexto de la crisis socioambiental y económica que atraviesa la humanidad, la noción de resiliencia utilizado inicialmente en la física ${ }^{6}$ y posteriormente en la ecología vuelve a acogerse como categoría paradigmática que intenta dar comprensión y explicación a diversos procesos dado en entidades sociales ante efectos perturbadores.

En el campo de la ecología le corresponde a Holling (1973) formalizar el concepto de la resiliencia como parte del cuerpo de la teoría ecológica. Posteriormente, el concepto sufre un salto paradigmático: de su uso en la teoría ecológica pasa a incorporarse hacia otros campos en el que intervienen de manera explícita los intereses productivos de los ecosistemas. Este salto representa una transformación epistémica importante en los estudio ecológicos (o de la ecología humana) y cada vez más recurrida en el tema de la construcción de la sustentabilidad, pero también de otras esferas de la sociedad. El mismo Holling ha experimentado estas metamorfosis en su discurso académico (Holling y Walker, 2003). Sobre esta variedad de significaciones de la resiliencia ecológica descansa la pretensión de constituirse en un concepto con capacidad para la compresión de las complejidades de los sistemas, ya sea para entenderse como "la capacidad de un sistema para mantenerse a pesar de su trastorno, sin pasar por un estado nuevo... [o para definirse] como la capacidad de un sistema de regresar a su estado inicial” (Martínez-Alier, 2004: 69).

Sin embargo, dentro del campo de la ecología prevalece un debate en la selección de los indicadores más adecuados para el monitoreo y estu- 
dio de la resiliencia ecológica. Aún más, a pesar de la pretendida objetividad de las ciencias ecológicas, existen diversas interpretaciones sobre la utilidad de la noción de la resiliencia ecológica para explicar las respuestas de los ecosistemas a determinadas perturbaciones. Uno de los primero puntos de debate fue el cuestionamiento sobre la existencia de un proceso de sucesión ecológica unilineal que se manifestaría en una "comunidad clímax" como parte de un modelo de "estado estacionario" del ecosistema. En contraparte surgirán otras formulaciones que planteaban la posibilidad de la existencia de múltiples estados estacionarios, y con ello de diferentes niveles de resiliencia ecológica (Walker, 2005). El problema no es trivial, en el se refleja diversas concepciones de apropiación, por ejemplo entre los diferentes sistemas de silvicultura.

En la esfera de las ciencias sociales la incorporación de la noción de resiliencia se empezó a expresar principalmente desde la psicología; principalmente para referirse a las respuestas "positivas" de los individuos que se enfrentaron ante un acto perturbador o adverso. La noción de resiliencia toma auge primero desde los países anglosajones como Inglaterra (Rutter, 1993) y Estados Unidos de Norteamérica Werner, 1994) y luego se propaga a los otros países de Europa occidental (Francia, Países Bajos, Alemania y España), para finalmente aterrizar en América latina.

Desde esta misma distribución geográfica se han manifestado tres corrientes intelectuales de la noción de resiliencia social: "la norteamericana, esencialmente conductista, pragmática y centrada en lo individual; la europea, con mayores enfoques psicoanalíticos y una perspectiva ética, y la latinoamericana, de raigambres comunitaria, enfocada en lo social como lógica de respuesta ante problemas del contexto” (Suárez, 2004:19). Paralelos a estos enfoques han surgido otras corrientes enfocadas a las diversas etapas del individuo (la infancia, adolescencia, la tercera edad) o hacia temas emergentes como las víctimas de violencia/guerra/terrorismo, discapacidades, el cambio climático, la educación y pedagogía, o el impacto de la era neoliberal.

Como ya se ha indicado, en este trabajo interesa destacar la noción de resiliencia social no como sinónimo de resistencia ante el efecto de perturbaciones (internas o externas); sino como un concepto que trata de incluir otros componentes, entre los que destacan los siguientes ante la incertidumbre y cambios del entorno: la respuesta; la auto organización; el aprendizaje; y la adaptación (Brenson-Lazan, 2003; Nadia et. al., 2006).

\section{La racionalidad económica neoliberal: catalizador de perturbaciones socioambientales}

La racionalidad económica está atravesando por crisis de tipo ideológico, coyunturales y estructurales. Ante ello el capital ha reactivado sus estrategias con un fuerte impacto en la sociedad civil y el ambiente. En este 
entorno se hace necesario la exploración de praxis sociales desde las cuales no solo se enfrente (resista) las consecuencias de tal crisis civilizatorio; sino que contribuya a la construcción de respuesta alternativas. Es decir, se hace necesario indagar procesos de construcción de resiliencia social.

Este asunto tiene mayor relevancia no solo académica, sino política para el caso de los pueblos latinoamericanos. Por una parte el papel asignado en Latinoamérica dentro de este entorno de crisis civilizatoria es fundamental para el desarrollo de una sociedad poscapitalista. El agotamiento del sistema capitalista financiero obliga al sistema capitalista a la búsqueda de oxígeno desde las bases de la economía real. La riqueza de recursos naturales (minerales, energéticos, genéticos) que poseen los pueblos latinoamericanos es uno de los últimos reductos que tiene el sistema capitalista para prolongar su crisis a partir del insumo las bases de su economía real. Pero por otra parte, gran parte de los territorios que poseen esta riqueza de recursos naturales está en los pueblos indígenas. Ello representa un fuerte obstáculo para la continuación de las estrategias de acumulación de la racionalidad económica en crisis.

Así, los pueblos indígenas están sometidos a diversas perturbaciones desde la racionalidad económica. A continuación se hace una descripción de estas con el fin de identificar la heterogeneidad de facetas en que se manifiesta y por ello la complejidad de respuestas comunitarias.

\section{Perturbaciones hacia el modelo político-económico de los estados nación: la instauración del modelo neoliberal}

Polanyi (2003) describe de una manera muy puntual el papel transformador de la racionalidad económica durante la fase de la revolución industrial, lo que identifica como la gran transformación del capitalismo hacia una economía de mercado. A finales del siglo XX se da otro gran salto en los procesos de la acumulación del capital: la globalización económica bajo el modelo neoliberal. Éste es un proceso que alcanza su máxima representación de transformación durante el último cuarto del siglo pasado y hasta le fecha. Desde esta se impulsan nuevos escenarios que son fuertes factores de perturbación socioambiental, entre los que destacan los siguientes aspectos descritos por Altvater y Mahnkopf (2002):

a) Reconstrucción del poder de los gobiernos locales manifestado en una crisis del Estado de bienestar. Se trata de las políticas de reforma del Estado hacia una mayor intervención para el desarrollo de una economía de libre mercado (adelgazamiento del Estado) ${ }^{7}$;

b) Ampliación de las relaciones económicas fuera de las fronteras de los Estados-nación; tal como lo representa para el caso de México el paradigmático tratado de libre comercio de Norteamérica (TLCAN). Ello implica no solo el fomento de un intercambio económico desigual, sino también ecológico (Martínez-Alier, 2004); 
c) Incorporación de nuevas reglas de negociación en el marco internacional, en el que la Organización Mundial de Comercio (OMC) figura como una de sus instituciones centrales;

d) Surgimiento de una nueva dimensión de los poderes geoestratégicos (militares y el uso de la violencia), tal como quedo de manifiesto en varios actos militares como la invasión a Irak sin previa mediación a través de la Organización de las Naciones Unidas (ONU).

e) El acento de la gravedad e interrelación de las crisis financieras, tal como aconteció con el impacto que está causando el estallido de la crisis de octubre del 2008 en los Estados Unidos de Norteamérica; y

f) El papel del desarrollo tecnológico en materia de transporte y comunicación como elementos vinculados con la generación de plusvalía.

Como lo mencionan Altvater y Mahnkopf (2002:5-6), todas estas transformaciones son posibles gracias al insumo de combustibles fósiles como elemento fundamental para la acumulación del capital y para la degradación ambiental.

\section{Perturbaciones violentas: la doctrina del shock}

En complemento al punto anterior, habrá que señalar que entre las "nuevas" estrategias de esta fase de la globalización económica se destaca un efecto perverso para el manejo de algunos de los efectos de la crisis ambiental como tsunamis, ciclones, golpes de estado, actos terroristas, etc. Klein (2007) ha denominado a estas estrategias como el capitalismo del desastre dentro de la "doctrina de shock". Es decir, como "los ataques organizados contra las instituciones y bienes públicos, siempre después de acontecimientos de carácter catastróficos, declarándolos al mimo tiempo atractivas oportunidades de mercado” (Klein 2007:26).

Durante más de tres décadas, Friedman y sus poderosos seguidores habían perfeccionado precisamente la misma estrategia: esperar a que se produjera una crisis de primer orden o estado de shock, luego vender al mejor postor los pedazos de la red estatal a los agentes privados mientras los ciudadanos aún se recuperan del trauma, para rápidamente lograr que las $<$ reformas $>$ fueran permanentes (Ibid: 27)

Esta nueva estrategias es relevante en el tema de la resiliencia social, pues al aumentar la incidencia de los fenómeno naturosociales se ha crecentado el potencial de su uso de esta estrategia dentro de la globalización económica, tal como Klein lo describe para el caso de el Huracán Katrina en Nuevo Orleans en el 2005, o el caso del tsunami en Indonesia en el año del 2004. Este tipo de acciones son promovidas desde el Estado. Es un sistema que

“elimina los límites en el gobierno y el sector empresarial... [se da] 
una gran trasferencia de riqueza pública hacia la propiedad privada -a menudo acompañada de un crecimiento el endeudamiento-, el incremento de las distancias entre los inmensamente ricos y los pobres descartables, y un nacionalismo agresivo que justifica un cheque en blanco en gastos de defensa y de seguridad” (Ibid: 39).

Existe un asunto de relevancia política adicional en esta doctrina del Shock. Da invisibilidad a la fuerte relación que hay entre las acciones derivadas del shock en la población y el papel del libre mercado en su fomento, tal como sucedió en el caso del golpe de Estado en Chile como atentado contra los derechos humanos de la población y la relación con la instauración del libre mercado como modelo de sociedad (Ibid).

\section{Perturbaciones estructurales: la crisis del capitalismo}

Hoy la crisis económica, social y ambiental es un reflejo de la crisis del proyecto civilizatorio capitalista, y con ello de sus premisas de ciencia, de desarrollo, de progreso. El diagnóstico sobre la naturaleza y alcances de la manifestación de la crisis financiera del 2008 y su continuidad ponen en evidencia que estamos frente a un proceso inédito dentro de la racionalidad económica capitalista. Voces tan disímbolas como el diagnóstico crítico presentado por Immanuel Wallerstein (2003) coincide con postura conservadora de George Soros (1999): ya no se trata de una crisis temporal; sino definitiva de la lógica de acumulación de tipo capitalista. En el mismo sentido concuerdan los análisis de otras instituciones como el Movimiento AntiUtilitarista de las Ciencias Sociales.

El relativo consenso del diagnóstico la crisis del sistema capitalista presenta, no obstante divergencias en sus causas y en sus estrategias hacia un poscapitalismo. Se hace evidente que tal crisis responde a causas de tipo interno inherentes al sistema capitalista, desde las ya anticipadas por Marx sobre la crisis de la producción, y ahora la crisis del sistema especulativo (capitalismo financiero). Pero también se ha resaltado una causa de tipo externo: el límite biofísico, de la biosfera, de la naturaleza para proporcionar fungir como portadora de insumos, de regulación de procesos (biogeoquímicos) y de sumidero.

La crisis del capitalismo manifestada en su crisis financiera del 2008 ya no se puede soportar desde el ámbito de la economía real; es decir, de la valoración-trabajo. El pacto establecido entre capital-trabajo después de la crisis de 1929 se agotó. Las medidas keynesianas ayudaron a aliviar tal crisis, y el Estado asumió el papel de administrador del capital, pero a la vez proporcionó gobernabilidad a través del establecimiento de políticas de bienestar social. El pacto que expresaba un relativo acompañamiento entre aumento de productividad y de salarios se empezó a agotar desde la década de los años de 1980, y tiene su máxima expresión en el simbólico “Derrumbe del muro de Berlín” y la ideología del modelo neoliberal. Pensadores como Fucuyama (1992) plantaron que estábamos ante el fin de los "metarrelatos"; de ahora en adelante el desarrollo de la humanidad se 
consagraría a partir del triunfo y matrimonio de dos de las instituciones emergidas de la modernidad capitalista: democracia (representativa) y mercado. Hoy ante la crisis de capitalismo se ha sepultado el papel del mercado como el dogma que dominó como panacea de la regulación de la sociedad. El Estado ha consagrado -ya no en la oscuridad- su papel como el único mecanismo para enfrentar la crisis.

\section{Perturbaciones ideológico-políticas: el liberalismo individual como eje del pensamiento único y la ausencia de la comunidad}

El tema de la relación entre las entidades como el "individuo” y los "grupos” se constituyó en uno de los principales ejes de reflexión de la época moderna y hasta la actualidad. El debate entre el liberalismo y el comunitarismo ha resurgido ante la crisis del modelo civilizatorio. Desprendido del proceso de extinción del orden feudal, de sus estamentos y de la legitimidad de sus instituciones, la noción de “individuo” ocupa un lugar central en la reflexión y actuar político y económico de la época moderna. La igualdad jurídica entre personas empieza a nacer como una idea de la modernidad. El hombre empieza a pensarse como no subordinado a las instituciones de la comunidad feudal; sino, como el eje del sistema público. Visto así, entonces la sociedad es entendida como un agregado de elementos autónomos: el individuo.

Ante la “artificialidad” de los órdenes sociales del feudalismo basados en premisas metafísicas o divinas, el individuo durante la emergencia de la modernidad es pensado como la unidad natural; por tanto, con derechos inherentes. La citada relación sociedad-Estado empieza a pensarse como una creación de voluntades de los hombres; más específicamente, del individuo. La sociedad es un contrato entre individuos dirigido para su protección. Con la modernidad se descubrió la existencia del hombre como individuo, y se afirmó las ideas de la libertad y de igualdad materializadas en la revolución francesa.

La transformación de la dinámica y ritmos de la acumulación del capital dado en el siglo XVIII va acompañada y justificada desde una perspectiva específica del pensamiento económico: los clásicos, representados por Adam Smith (1723-1790) y David Ricardo (1772-1823). Con Smith empieza a gestarse el individualismo metodológico como premisa de su teoría económica; afirma que "No es la benevolencia del carnicero, del cervecero o del panadero la que nos procura el alimento, sino la consideración de su propio interés”.

La modernidad occidental, con todo y su crisis, proporciona las instituciones desde la cuales se da la actual condición posmoderna: el individualismo, el mercado, la propiedad privada, la democracia representativa (figura 1.). Desde finales del siglo XX, ahora el liberalismo de la modernidad ya no es disruptivo; sino uno “desencantado". Se expresa como “pasamiento único” aceptado sin reparos por varias corrientes políticas e incluso opuestas tanto de derecha como de izquierda (Villoro, 2003:21). 
Villoro identifica a cuatro como las “ideas-lema” emergidas de este liberalismo renovado consagrado como el pasamiento único:

a) la libertad individual. Ante el despotismo de la figura del Estado como el caso del holocausto, el llamado a los derechos humanos se reconstituye como una herencia de la modernidad de alto valor.

b) la democracia. Entendida de manera muy laxa como el conjunto de procesos de elecciones, representatividad, división de poderes, decisiones por mayoría, etc. es tratada de recuperar como un valor para enfrentar los modelos de gobierno de corte dictatorial;

c) el adelgazamiento del Estado. Es otro de los valores impulsados desde el liberalismo, en el que pretenden asignarle un papel orientado al impulso de la empresa privada; y

d) la meta de la productividad y desarrollo, lo que implica la libración de las fuerzas del mercado.

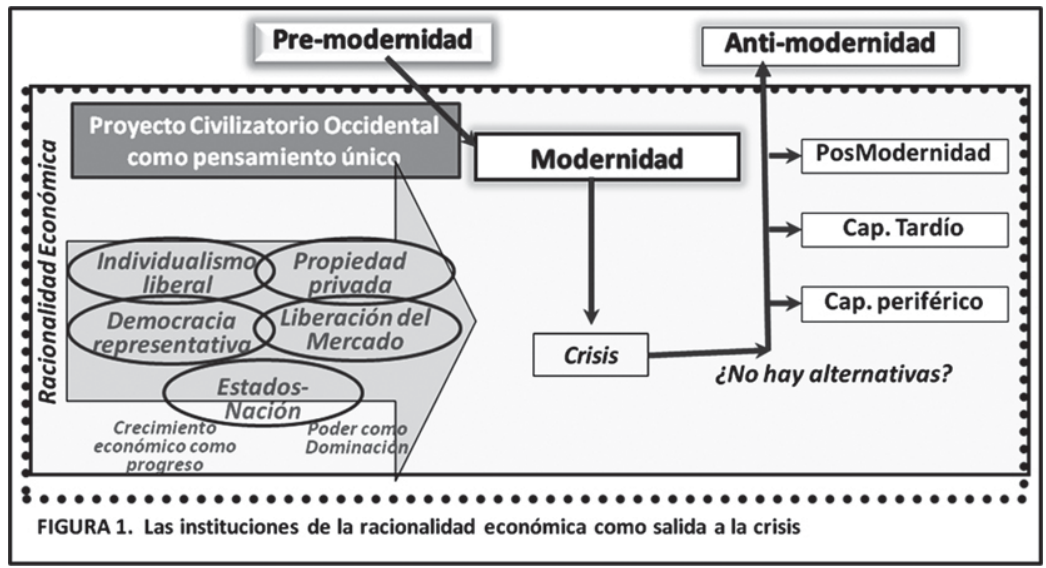

Un asunto mencionado por Villoro es de alta relevancia al tema abordado; es decir, del papel de la asociación comunitaria ante los efectos perturbadores de la racionalidad económica en su fase neoliberal: "el nuevo liberalismo nos ha hecho despertar del sueño falaz de un Estado que lograra la felicidad de todos; pero para ello tuvo que pagar un precio: la exclusión.” Adicionalmente indica que no todos los individuos son libres si no todos están en situación de convertir en realidad sus elecciones de vida razonables, pues para favorecer esta libertad en igualdad se suponen dos cosas: a) igualdad de las condiciones para satisfacer las necesidades básicas (alimentación, vivienda, protección contra la enfermedad y muerte violenta), pues la carencia de estas impide toda elección; y b) la igualdad de 
oportunidades sociales (educación, trabajo, cuidado de la salud) para poder ejercer nuestras elecciones.

De ahí que considere que en una sociedad que deposita sus máximos valores en el individualismo (derechos, protección de la vida) ocasiona una desatención de los valores colectivos, por ello advierte la necesidad de asumir “el peligro de la disgregación de los lazos comunitarios basados en la conciencia de pertenencia común a una misma entidad social... tal parece que la libertad individual requería de una ausencia, la de la comunidad” Villoro, (2003:24-5).

Villoro como Bonfil reconocen las aportaciones de la comunidad indígena en la construcción de racionalidad alternas a la economía neoliberal:

“Las formas de vida de las comunidades tradicionales no son exportables sin más a la sociedad moderna. Sin embargo, dan testimonio de otros valores posibles que permitan vencer las taras del individualismo moderno. Nos revelan la posibilidad de otra forma de dar sentido a nuestras vidas colectivas... Son un ejemplo, una llamada de atención: <Cuidado -parecen decir- no ha llegado el fin e la historia. Existen alternativas a su sociedad egoísta y excluyente. Atrévanse a intentar formas de vida más altas>” (Ibid: 32).

En el siguiente apartado se describe parte de las características de la organización comunitaria dada en gran parte de los pueblos de la Sierra Juárez de Oaxaca, la cuales se denomina como comunalidad y sirven de referente para territorializar en tema de la resiliencia social.

\section{La reconfiguración del comunitarismo: la construcción de comunalidad y procesos autonómicos}

\section{La comunalidad}

Una característica de los diversos pueblos con ascendencia de la cultura mesoamericana es la puesta en práctica e innovación constante de una forma de organización comunitaria. Estas prácticas son derivadas de su alto grado de interculturalidad e interrelación con algunas instituciones de la colonia española (Chance y Taylor, 1987; Lockhart, 1985; Taylor, 1972). Intelectuales orgánicos de la Sierra Juárez de Oaxaca han aglutinado esta forma compleja de organización comunitaria desde la categoría de comunalidad (Martínez Luna, 2010; Díaz, 2007). La comunalidad representa una contribución epistémica que da cuenta de procesos de apropiación de la naturaleza de una manera alterna a la ortodoxa visión e instituciones del proyecto civilizatorio occidental (ver figura 1). De la comunalidad se aglutinan un conjunto de atributos institucionales comunitarios, no necesariamente homogéneos, pero que en términos generales presentan los siguientes atributos: 
- La comunalicaracia, alimentada por el ejercicio cotidiano en la asamblea ciudadana, comunal y las diversas instancias de vigilancia. Es decir, en gran parte de estas comunidades se despliega la democracia directa (uso constante de la asamblea para informar acciones, toma de decisiones y la rendición de cuentas), pero también la representativa. Ello contribuyó a que en Oaxaca, las reformas en materia electoral permiten incorporar el sistema de normas consuetudinarias ("usos y costumbres”) para elegir a sus autoridades municipales (Hernández Díaz, 2007);

- La organización del trabajo comunitario, el cual se desarrolla sin compensación monetaria, sino ligado a otro tipo de valoraciones como el desarrollo de prestigio local o de compromisos impuestos desde la comunidad "para seguir perteneciendo a ella”. Se expresa a través de una diversidad de actividades, entre estas, a las siguientes: en la asamblea para la decisión; el cargo para la coordinación; el tequio para la construcción; y la fiesta para el goce (Martínez Luna, 2003);

- La posesión territorial comunitaria. No sólo es factor de cohesión social basada en el bien común definido cultural e históricamente (como puede la tenencia de la tierra comunal), sino también es vital por la preservación del espacio vital. Como la base territorial para la transformación, la expresión de los conocimientos específicos sobre la utilización de los recursos naturales y como la base material para la autonomía política y productiva;

- La construcción de identidad cultural es una noción compleja que se alimenta de diversas vertientes, entre ellas el sustento territorial y de las representaciones religiosas espirituales, la ritualización del pasado en el presente, la cosmovisión, la música, el apego a la tierra. Las fiestas patronales realizadas por las comunidades y los barrios de manera anual, constituye un ejemplo de este tipo de representaciones (Díaz 2007). En este proceso hay un elemento significativo y novedoso para la construcción de identidades: los proceso migratorios, en donde "El drama de la desterritorialización se convierte en estrategia para no perder la cercanía con la comunidad de origen” (Rangel y Sánchez 2001:86).

- La cosmovisión. En el que se agrupa y se explora todas aquellas manifestaciones sobre la percepción cultural de la naturaleza. Por ello su trascendencia en la indagación para relacionarla con los procesos de apropiación social de la naturaleza.

De esta forma, la comunalidad no es la representación conjunta de los intereses individuales sobre los colectivos como sucede en la noción de "contrato social” de Hobbes o de Locke. No se entiende como

"un convenio [donde] cada quién hacía el contrato para resguardar su interés particular; si el contrato, la asociación política, no lo resguardaba, me siento con todo el derecho de ir en contra porque acepté el contrato en función de mi interés egoísta, y si no responde a él, 
me rehúso a continuarlo” (Villoro, 2003: 48-9).

En el caso de las citadas praxis campesinas se puede entender como un contrato en el que

"puesto que lo acepto buscando el bien de todos por medio de la voluntad general, aunque vaya en contra de mi interés personal, seguiré fiel el contrato... La democracia es, en este segundo tipo de contrato, una asociación política que a la vez, necesariamente, es ética, porque es la manera de mantener una entidad pública que garantice la libertad de todos, y que sea, por lo tanto, garante de autonomía” (Ibid).

Figura 2. Modelo de contraste entre instituciones del Proyecto Civilizatorio de la modernidad americanizada y el derivado de la cultura mesoamericana en su articulación con instituciones de la colonia

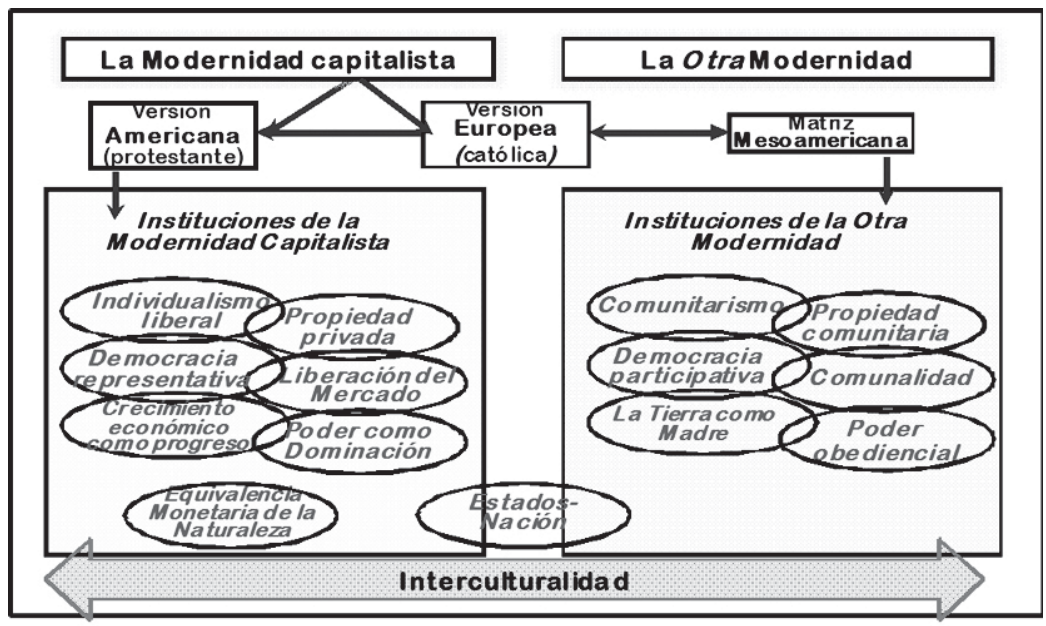

Fuente: Elaboración propia

La comunalidad se presenta como eje de estrategias campesinas alternativas frente al modelo hegemónico emanado de la racionalidad económica capitalista. En esta perspectiva, la noción y construcción de la autonomía desempeña un papel fundamental para definir la direccionalidad de este ethos comunitario y su posibilidad para enfrentar la exclusión social y la insustentabilidad.

Se indica que aunque las estrategias de reproducción de las comunidades indígenas siguen ligadas a las dinámicas que imponen las instituciones del mercado y del Estado, en las comunidades de la $\boldsymbol{S J O}$ se encuentran 
racionalidades con alto potencial para diferenciarse o coexistir con la lógica de la racionalidad económica neoliberal. Se plantea, en esta perspectiva, que el grado de comunalidad como nuevo ethos comunitario y la construcción de la autonomía local y regional son fundamentales en la construcción de resiliencia social.

\section{Bases para la reconfiguración de la comunalidad: la construcción de autonomía comunitaria}

En este punto se destaca la relevancia de la construcción de la autonomía como proceso para la producción y reproducción del ethos comunitario frente a los poderes del mercado y de las expresiones del Estado neoliberal. Proceso que se forja en la comunidad local, pero que tiene su mayor expresión en la constitución de redes de comunidades o a nivel regional; de ahí la importancia de la construcción de alianzas entre comunidades.

El ensayo parte de la premisa de que uno de los resultados del desarrollo autonómico se manifiesta en la capacidad para la generación de excedentes. El grado de integración o desfase de estos procesos a las lógicas de acumulación capitalista, determinará en gran medida los alcances de la autonomía financiera. Así, por ejemplo, las remesas por migración pueden o no contribuir a la diversificación de la esfera productiva o de goce de la comunidad en función al grado del ethos comunitario alcanzado. Es decir, incorporarse o no a la esfera de los proceso de acumulación capitalista o a la generación de excedente no proletarios (Barkin y Rosas 2005). Entre los principales procesos que integran este concepto, son:

- La formación político-cultural desde la cual se define la relación política entre comunidades (redes) y el Gobierno (sobre todo estatal y federal). En esta se expresan las relaciones ya sea de subordinación, resistencia o mayor autonomía política frente al gobierno. Es una esfera donde se construyen lazos entre la sociedad política y la sociedad civil; se expresan las relaciones estructural versus cultural y la Interculturalidad Multiculturalidad (Otero 2006);

- El desarrollo de las fuerzas productivas comunitarias, en las que se expresa el desarrollo tecnológico, los grados de apropiación tecnológica y la posibilidad de la diversificación productiva (empresas ecoturísticas, plantas de purificación de agua, tiendas comunitarias, etc.). Se manifiesta también, en actividades amplias como las llamadas "multifucionales" o la "pluriactividad" (Giarraca, 2000). Asimismo, se relaciona con el desarrollo de proceso productivos más eficientes (energética, material y financieramente) y generadores de mayor "valor comercial" como lo representa, por ejemplo, la transformación de proceso forestales únicamente de extracción de madera a otros como la elaboración de muebles para el caso de las comunidades de la Sierra Juárez de Oaxaca y de Michoacán; 
- La diversificación del mercado. Proceso basado sobre la premisa de una necesaria búsqueda de alternativas ante las esferas del intercambio y de la circulación fuera de las acciones azarosas del mercado. Estrategias importantes en la esfera del comercio justo basado en una economía solidaria (Cadena, 2005).

- La formación de redes de apoyo en la que incluye la interacción de diversas instancias de la sociedad civil y de instituciones de educación y desarrollo tecnológico. En este sentido se ubican los trabajos desarrollados por los círculos de trabajo indicados al inicio, en el que se parte de estas premisas para el despliegue de actividades con las organizaciones sociales y productivas locales. En este punto destaca de manera notable la pertinencia de las propuestas metodológicas usadas en el campo emergente de la economía ecológica como la "ciencia posnormal” y la "evaluación multicriterio social”.

- La soberanía alimentaria en la que se definen las estrategias de producción, abasto, intensidad de uso. Se trata de un proceso complejo y polémico, como lo advierte Barkin (1998), y que se presenta frente a los procesos de la integración económica internacional que promueven la especialización a través del monocultivo usando de manera intensiva insumos energéticos y agua (virtual) ;

\section{Conclusiones}

Las acciones de la racionalidad económica sobre las poblaciones indígenas se han intensificado en la última década. El Estado y el capital ubican a las comunidades indígenas como obstáculos de un modelo específico de desarrollo, de progreso; de ahí la necesidad de impulsar acciones externas que permitan sacarlas del atraso. Este modelo está vinculado de manera directa con las premisas e instituciones de la modernidad occidental: el crecimiento económico ilimitado como sinónimo de progreso, la democracia representativa como estrategia de gobernabilidad; la propiedad privada como motor de inversión; el interés individual como base ética de un contrato social; el mercado como el mecanismo para la asignación eficiente y organización de la sociedad. El modelo evade el análisis de los costos ambientales y sociales.

La injusticia ambiental manifestada en una desigual distribución de los conflictos económicos y ambientales distributivos es una evidencia de la instrumentación de tal dogma. Pero ya no se trata solo de una crisis socioambiental, se trata de una crisis del proyecto civilizatorio occidental. El ensayo trató de explora el papel de la reconfiguración comunitaria expresada en la comunalidad como una estrategia no solo para resistir los embates perturbadores de la racionalidad económica en los pueblos indígenas; sino y sobre todo de la necesidad de ofrecer respuestas alternativas y creativas. 
La noción de resiliencia social permite integrar esa orientación ético-político de las respuestas de las comunidades indígenas, pues esta noción incluye el componente de la necesidades de la auto organización, el aprendizaje y la adaptación (Brenson-Lazan, 2003; Nadia, 2006). Es decir, no contradice la necesidad de innovar la tradición; tal como lo han hecho los pueblos indígenas. Un eje fundamental de tales procesos es la construcción de espacios autonómicos comunitarios, y de la edificación de alianzas comunitarias. Desde este enfoque se destaca la participación social en la construcción de nichos de sustentabilidad como contribución epistémica y de un diálogo de saberes e intercultural.

La respuesta de las comunidades indígenas a las acciones violentas (shock) del Estado o del capital desde la construcción de la comunalidad son signos de construcción de resiliencia social. Al respecto Klein (2007) señala que algunas características de las comunidades que hacen más efectiva las respuestas al shock, entre estas las siguientes: a) Existe una memoria histórica profunda. Dado que el shock tiene que ver con la sorpresa, entonces las comunidades con esta presencia histórica tienen mayor capacidad de identificar determinados patrones, y con ello relativizan el nivel de sorpresa; b) Existe una permanente sospecha frente a las acciones del Estado; ello evita que al estar en estado de Shock se genere un estado de "regresión" que busca la identidad paterna o protectora; la cual es asumida generalmente por el Estado; y, c) la existencia de una narrativa muy fuerte de "como el mundo debería de funcionar".

En el caso concreto de otras perturbaciones violentas, pero no abruptas la comunalidad también tiene ejemplos de manifestarse como un proceso de construcción de resiliencia social. Ello se puede mostrar las luchas frente a las concesiones forestales y mineras dadas en la Sierra Juárez de Oaxaca (Fuente y Barkin, 2011). Estas comunidades poseen un conjunto de instituciones que favorecen la exigencia del derecho de consulta y de expresar otras nociones de desarrollo, y en su caso de sustentabilidad; valores altamente importantes en la resiliencia social. La dinámica asociación entre el territorio y la comunalidad deriva de la importancia del territorio como la base de identidad cultural y de sustento de vida; la comunalidad es un instrumento político-cultural. Se debe de indicar, además, que estas praxis campesinas expresadas en la comunalidad no son estáticas. Requieren cotidianamente la construcción de espacios autonómicos; los cuales son frágiles y demandan su constante reconfiguración en función a las señales de las instituciones de la racionalidad económica de corte neoliberal: el Estado y el mercado. Su configuración implica, al mismo tiempo, el enfrentamiento de diversas luchas políticas no solo al exterior, sino al interior de las mismas comunidades. Estas luchas se están dando actualmente en la Sierra Juárez de Oaxaca en diversos ámbitos de la sociedad rural (Ibid, 2011).

Las enseñanzas de estas luchas comunitarias en la construcción de la resiliencia social son en diversos niveles. Desde una perspectiva epistémica muestra a la categoría de comunalidad como una institución 
fundamental para impulsar lenguajes de valoración de la naturaleza alternos a la visión de la economía global. Pero por otro lado es política: muestra que en la medida el Estado interviene de manera autoritaria o violenta genera disenso social; pero al mismo tiempo puede ser catalizador de respuestas organizadas de los grupos sociales (como la comunalidad) que logran identificar que han sido excluidos como ciudadanos en la construcción del proyecto de nación.

Este trabajo es una invitación analítica a escuchar y entender otras voces en la conformación de los nuevos escenarios socioambientales y de justicia ambiental en el proyecto de nación; voces para un diálogo de saberes (Leff, 2004) y diálogo intercultural (Zemelman y Quintanar, 2007). Así, frente a la concepción única de modernidad o posmodernidad desde el modelo de la globalización económica, el trabajo se inscribe en la posibilidad de una trans-modernidad e interculturalidad (Dussel, 2006), o de una modernidad alternativa (Toledo, 2000). Pero también es un llamado de atención sobre la necesidad de revisar nuestros paradigmas académicos. 


\section{Notas}

${ }^{1}$ Trabajo presentado en el Coloquio Internacional "Hacia la construcción de un nuevo paradigma social”, en la UAMX celebrado del 5 al 7 de marzo del 2012.

2 Acomodo de las leyes de inversión en función a la lógica de la racionalidad económica neoliberal.

${ }^{3}$ En la lista de Forbes, sigue pareciendo un mexicano entre los primeros lugares.

${ }^{4}$ Toledo (2006:28) se refiere a estos como aquellos "que han dejado de ser meros 'fenómenos naturales' para volverse fenómenos socialmente producidos... son la consecuencia de una complejidad de causas y efectos donde las irracionalidades urbanas e industriales se combinan con los manejos inadecuados de recursos naturales"

${ }^{5}$ Tal como lo señala Navarrete (2004:22), las clasificaciones étnicas no solo cumplen una función conceptual para comprender la realidad, sino que corresponde a una construcción socio-histórica, "la cual también cumple funciones sociales y políticas, pues permite organizar las relaciones sociales”

${ }^{6}$ En este campo se entiende como un atributo de ciertos materiales para recuperar su estructura (forma) ante diversos niveles de presiones.

${ }^{7}$ Por ello, Otero (2006) refiere a este proceso como una neoregulación del Estado, en vez de desregulación. Mantiene que el estado sigue desempeñando un papel fundamental en el cambio de reglas a favor de las corporaciones. Esto se puede ejemplificar con la participación del gobierno estadounidense en el intento del "rescate" financiero a bancos y compañías automotrices durante los últimos meses del año 2008. 


\section{Bibliografía}

Altvater, Elmar y Birgit Mahnkope (2002), Las limitaciones de la Globalización. Economía, ecología y política de la globalización. Siglo XXI editores-CIICS/UNAM, México:

Barkin D. y M. Rosas (2006), “¿Es posible un modelo de acumulación alternativo?”. En Revista Polis. Vol. 5(12), http://www.revistapolis.cl/13/ ind13.htm (consultado el 26 de agosto del 2009). Chile

Barkin, David (1998), Riqueza, pobreza y desarrollo sustentable. JusCECODES-Centro Lindavista. México.

Boege, Eckert (2008), Patrimonio Biocultural de los Pueblos Indígenas de México: Hacia la conservación in situ de la biodiversidad y agrodiversidad en territorios de los pueblos indígenas. INAH- CDI, México.

Bonfil B., Guillermo (1982), “Lo propio y lo ajeno: Una aproximación al problema del control cultural”. En La Cultura Popular. Adolfo Colombres, compilador. Premiá Editora, México.

Bonfil Batalla, Guillermo (2005), México profundo. Una civilización negada. Random House Mondadori, México.

Brenson-Lazan, G. (2003), Group and Social Resilience Building. URL: En línea www.communityatwork.com/resilience/RESILIENCIAENG.pdf (consultado el 8 de octubre del 2012)

Cadena B., F. (Coord.)( 2005), De la economía popular a la economía de solidaridad. Itinerario de una búsqueda estratégica y metodológica para otro mundo posible. FOMIX-ECOSOL-SEPUEDE, México, D.F:

Chance, J. y M. Taylor (1987), “Cofradías y cargos: una perspectiva histórica de la jerarquía cívico-religiosa mesoamericana”. En Antropología, Boletín Oficial del INAH, No. 14.

Díaz, F. (2007), “Comunidad y comunalidad”. En: Robles, S. y R. Cardoso (compiladores), Floriberto Díaz. Comunalidad, energía viva del pensamiento. UNAM, pp. 34-50, México.

Díaz, Floriberto (2007), Comunalidad, energía viva del pensamiento. UNAM, México.

Dussel, Enrique (1992), “La introducción de la transformación de la filosofía de K.-O. Apel y la filosofía de la liberación. Reflexiones desde una perspectiva latinoamericana”. En: Apel, K.-O, et al. Fundamentación de la ética y la filosofía de la liberación. México; Siglo XXI editores, pp. 45104 
Dussel, Enrique (2006b), Filosofía de la cultura y la liberación. UACM, México, D.F

Elizalde, A. (2012), “Aporías de la sustentabilidad capitalista”: Mesa de trabajo del Coloquio Internacional Hacia la construcción de un nuevo paradigma social. UAM-X, México. D.F

Esteva, Gustavo (2012), “Pensar desde el Abismo”. En II Seminario Internacional de reflexión y análisis "Planeta tierra: movimientos antisistémicos”, Universidad de la Tierra, San Cristóbal de las Casas, Chiapas, 30-31 de diciembre de 2011, 1-2 de enero de 2012. En línea: http://zapateando2.wordpress.com/2012/01/15/pensar-desde-el-abismo/ (consultado el 8 de octubre del 2012)

Fuente, M.E. y D. Barkin (2011), “Concesiones forestales, exclusión y sustentabilidad”. En Desacatos, Nº. 37: 93-110, México, D.F.

Fukuyama, F. (1992), The End of History and the Last Man. Free Press, New York, NY.

Giarracca, Norma (comp.) (2000), ¿Una nueva Ruralidad en América latina? CLACSO, Buenos Aires.

Hernández-Díaz, J. (Coord.) (2007), Ciudadanías diferenciadas en un estado multicultural: los usos y costumbre en Oaxaca. Siglo XXI-IISUABJO, México, D.F.

Holling, C.S. (1973), "Resilience and stability of ecological systems”. In: Annual Review of Ecology and Systematics 4:1-23.

Holling, C.S. and Walker B.H. (2003), “Resilience defined”. In: International Society of Ecological Economics (ed.), Internet Encyclopedia of Ecological Economics. En línea: http://www.ecoeco.org/pdf/ resilience.pdf (consultado el 8 de octubre del 2012)

Klein, Naomi (2007), La Doctrina del shock. El auge del capitalismo del desastre. Ediciones Paidós Ibérica, Barcelona.

Leff, E. (2004), Racionalidad Ambiental. Siglo XXI editores, México, D.F.

Lockhart, J. (1985), Los nahuas después de la Conquista. FCE, México, D.F.

Martínez Alier, Joan (2004), El ecologismo de los pobres. Conflictos ambientales y lenguajes de valoración. Icaria-Antrazyt-FLACSO, Barcelona.

Martínez Luna, J. (2010), Eso que llaman comunalidad. CONACULTACAMPO-Fundación Harp Helú-Secretaria de Cultura-Oaxaca, Oaxaca. 
Morales O. C. (2011), Nueva Sociedad, Núm. 231, enero de 2011, Fundación, Buenos Aires.

Nadia P. Abesamis, Colleen Corrigan, Mark Drew, Stuart Campbell, Giselle Samonte (2006), Social Resilience: A literature review on building resilience into human marine communities in and around MPA networks, MPA Networks Learning Partnership, Global Conservation Program, USAID September 2006. En línea: http://www.reefresilience.org/pdf/ Social_Resilience_Literature_Review.pdf (consultado el 8 de octubre del 2012)

Navarrete, F. (2004), Las relaciones interétnicas en México. UNAM, México, D.F.

Otero, Gerardo (coord.) (2006), México en transición: globalismo neoliberal, Estado y sociedad civil. U.A. de Zacatecas/Simon Fraser University/ Miguel Angel Porrúa/ Cámara de Diputados, México, D.F.

Otero, Gerardo. (2004), ¿Adiós al campesinado?. Democracia y formación política de las clases en el México Rural. Miguel Angel Porrúa-UA de Zacatecas - Simon Fraser University, México, D.F.

Polanyi, Karl. [1944] (2003), La gran transformación. Los orígenes políticos y económicos de nuestro tiempo. México: Fondo de Cultura Económica.

Rangel L, C. y E. Sánchez S. (2001), “La construcción de las identidades étnicas en la montaña de Guerrero: entre lo terrenal y lo sagrado”. En Acta Sociológica 33, septiembre-diciembre, pp. 85-113. México, D.F.

Rutter, M. (1993), “Resilience: Some conceptual considerations”. In: Journal of Adolescent Health, 14, 626-631.

Soros, George (1999), La crisis del capitalismo global. La sociedad abierta en peligro, Plaza \& Janés, España.

Stavenhagen, Rodolfo (2008), Los pueblos indígenas y sus derechos. UNESCO, México, D.F.

Suárez Ojeda, Elbio Nestor (2004), “Introducción. Resiliencia y Subjetividad”. En: Melillo, Aldo; Suárez Ojeda, Elbio Néstor y Rodríguez, Daniel (compiladores). Resiliencia y Subjetividad. Los ciclos de la vida. Paidós. Tramas sociales. Buenos Aires.

Taylor, W.B. (1972), Landlord and Peasant in Colonial Oaxaca. Stanford University Press, Stanford, Ca.

Toledo, V. Manuel (2006), "Ecología, sustentabilidad y manejo de recursos naturales: la investigación científica al debate”. En Toledo, V.M.; 
Oyama,K. y Castillo, Al. Manejo, conservación y restauración de recursos naturales en México, UNAM, Siglo XXI, México D.F.

Walker L.R. (2005), Margalef y la sucesión ecológica. Ecosistemas. 2005/ 1, En línea:http://www.fcnym.unlp.edu.ar/catedras/ecocomunidades/70.pdf, (consultado el 8 de octubre del 2012)

Wallerstein, I. (2003), Después del liberalismo. Siglo XXI, UNAM 5 ed., México, D.F.

Werner, E. (1994), "Risk, resilience, and recovery: Perspectives from the Kauai longitudinal study”. In: Development and Psychopathology, 5, 503515.

Zemelman, H. y E. Quintanar (2007), Conversaciones acerca de interculturalidad y conocimiento. IPN-IPECAL, México, D.F.

Recibido: 15.10 .2012

Aceptado: 07.11.2012 